\title{
Crescimento radicular e produtividade de cana-de-açúcar em função de doses de vinhaça em fertirrigação
}

\author{
Root system distribution and sugar-cane production \\ under vinasse treatments
}

\author{
Cristiane de Conti Medina ${ }^{1 *}$; Carmen Silvia Vieira Janeiro Neves ${ }^{1}$; \\ Ines Cristina de Batista Fonseca ${ }^{1}$; Alberto Felipe Torreti ${ }^{2}$
}

\begin{abstract}
Resumo
Estudou-se a quantidade e a distribuição das raízes e a produção de cana-de-açúcar, cultivar RB 785148, em Latossolo Vermelho tratado com doses de vinhaça $\left(0,150,300,450\right.$ e $\left.600 \mathrm{~m}^{3} \mathrm{ha}^{-1}\right)$, em Londrina PR. Para avaliação das raízes, utilizou-se o método do perfil, sendo estas analisadas através de imagens digitais. Independentemente da dose, a aplicação de vinhaça aumentou a quantidade total raízes, sendo maior o enraizamento na camada de $0 \mathrm{a} 0,25 \mathrm{~m}$. Quanto à produtividade de colmos, as doses de $300 \mathrm{e}$ $450 \mathrm{~m}^{3} \mathrm{ha}^{-1}$ proporcionaram produtividades significativamente maiores que a testemunha $\left(0 \mathrm{~m}^{3} \mathrm{ha}^{-1}\right)$. Além de mais econômica, a dose de $300 \mathrm{~m}^{3}$ ha ${ }^{-1}$ resultou em maior enraizamento na camada de $0,25 \mathrm{a}$ $0,50 \mathrm{~m}$ de profundidade.

Palavras-chave: Saccharum spp, subproduto, raízes, latossolo.
\end{abstract}

\begin{abstract}
The aim of this study was to measure the amount and distribution of sugar-cane roots, variety RB 785148 , under vinasse treatments in a clayey Oxisol in Londrina - Paraná. The profile wall method was used. Roots were counted by analysis of digital images. Vinasse doses were: 0, 150, 300, 450 and 600 $\mathrm{m}^{3} \mathrm{ha}^{-1}$. A larger amount of roots was observed closer to the clump in all treatments. All vinasse treatments increased root amount, and $0-0.25 \mathrm{~m}$ layer presented more roots. An increase in total root amount was observed with increase of vinasse treatment, as a result of an effect on 0-0.25 m layer. Treatments 300 e $450 \mathrm{~m}^{3} \mathrm{ha}^{-1}$ presented sugar cane yield significantly higher than control. Treatment $300 \mathrm{~m}^{3} \mathrm{ha}^{-1}$ was considered economic interesting and had more roots on the $0.25-0.50 \mathrm{~m}$ soil layer.
\end{abstract}

Key Words: Saccharum spp, by products, roots, oxisol.

\section{Introdução}

O estudo do sistema radicular e o conhecimento dos fatores que influenciam seu crescimento e sua distribuição são importantes para compreender me- lhor o desempenho das plantas. As raízes têm seu desenvolvimento influenciado por vários fatores, destacando-se como principais os teores de nutrientes e de água, a resistência mecânica à penetração e a aeração do solo.

\footnotetext{
1 Professores do Departamento Agronomia, UEL, C.P. 6001, CEP 86.051-990, Londrina, PR., Tel. 43 3371-4555, E-mail: medina@uel.br

2 Acadêmico de Agronomia, UEL

* Autor para correspondência.
} 
Quanto maior o enraizamento de uma planta, maior sua capacidade de explorar o solo e aproveitar os nutrientes e a água disponíveis. Estudos realizados por Inforzato e Alvarez (1957) mostraram que a maior parte do sistema radicular da cana-de-açúcar localizase nos primeiros $0,30 \mathrm{~m}$ de solo. Korndörfer, Primavesi e Deuber (1989) estudaram a distribuição dos sistemas radiculares de cana-planta e cana-soca (variedades SP70-1143, SP71-799, SP71-6163, NA56-79 e RB72-5828) em um Latossolo Vermelho Amarelo álico, observando que, em cana-planta, 89 a $92 \%$ das raízes se situaram nos primeiros $0,30 \mathrm{~m}$, e, em cana-soca, 85 a $92 \%$ das raízes se situaram nos primeiros $0,40 \mathrm{~m}$, não sendo observadas diferenças significativas entre as variedades.

A vinhaça, resíduo da destilação do álcool, tem sido utilizada como fertilizante em cana-de-açúcar, promovendo alterações nas propriedades físicas, químicas e biológicas no solo, que, quando benéficas, geram aumentos de fertilidade, de porosidade e de retenção de água, colaborando para melhores desenvolvimento e produtividade da cana (GLÓRIA; ORLANDO FILHO, 1983).

Este trabalho teve como objetivo avaliar a influência de doses de vinhaça no crescimento do sistema radicular e na produtividade da cana-de-açúcar em Latossolo Vermelho.

\section{Material e Métodos}

O estudo foi conduzido em Latossolo Vermelho, na Fazenda Escola da Universidade Estadual de Londrina, em Londrina - PR. O clima da região é subtropical úmido, com chuvas em todas as estações, podendo ocorrer seca no período de inverno. A temperatura média anual é de $20,7^{\circ} \mathrm{C}$ e a altitude é de $566 \mathrm{~m}$. As coordenadas geográficas são $23^{\circ} 23^{\prime} \mathrm{S}$ e $51^{\circ} 11^{\prime} \mathrm{W}$ (CORRÊA; GODOY; BERNARDES, 1982).

A variedade de cana-de-açúcar utilizada foi a RB 785148 (PLANALSUCAR, 1988). No preparo do solo fez-se uma aração, na profundidade de $0,30 \mathrm{~m}$, duas gradagens niveladoras e a abertura dos sulcos.
O plantio foi efetuado em 19/10/1994, sendo utilizados colmos de 3 gemas cada, distribuídos nos sulcos, totalizando 9 gemas por metro. No plantio, foram utilizados: $20 \mathrm{~kg} \mathrm{ha}^{-1}$ de N (uréia), $90 \mathrm{~kg} \mathrm{ha}^{-1}$ de $\mathrm{P}_{2} \mathrm{O}_{5}$ (superfosfato simples) e $90 \mathrm{~kg} \mathrm{ha}^{-1} \mathrm{de}_{2} \mathrm{O}$ (cloreto de potássio). Passados 60 dias do plantio, foram aplicados $50 \mathrm{~kg} \mathrm{ha}^{-1}$ de uréia em cobertura.

O delineamento experimental foi de blocos ao acaso, com 5 tratamentos e 4 repetições. Os tratamentos constaram de $0,150,300,450$ e $600 \mathrm{~m}^{3}$ ha-1 de vinhaça aplicada após o $3^{\circ}$ corte da cana ( $2^{\mathrm{a}}$ soca), em 07/97. A composição química da vinhaça, segundo análise realizada no Laborsolo (Londrina - PR), pode ser observada na Tabela 1. Cada parcela foi constituída por 5 linhas de $8 \mathrm{~m}$, espaçadas de 1,20 m, obtendo-se em cada parcela $48 \mathrm{~m}^{2}$. Para as avaliações, foram consideradas as 3 linhas centrais da parcela, desprezando-se 1,50 m em cada extremidade, obtendo-se uma área útil de $18 \mathrm{~m}^{2}$. A produtividade foi avaliada após o $4^{\circ}$ corte $\left(3^{\text {a }}\right.$ soca) em $08 / 98$, por meio da pesagem dos colmos da área útil, sendo a cana colhida verde e os colmos despontados.

Tabela 1 - Composição química da vinhaça de caldo misto aplicada.

\begin{tabular}{lcccccc}
\hline Elemento & $\mathrm{N}$ & $\left(\mathrm{P}_{2} \mathrm{O}_{5}\right)$ & $\left(\mathrm{K}_{2} \mathrm{O}\right)$ & $\mathrm{Ca}$ & $\mathrm{Mg}$ & $\mathrm{S}$ \\
\hline Teor $\left(\mathrm{kg} \mathrm{m}^{-3}\right)$ & 0,28 & 0,12 & 2,40 & 1,10 & 0,24 & 5,48 \\
\hline
\end{tabular}

A avaliação do sistema radicular foi realizada pelo método da Parede do Perfil (BÖHM, 1979), imediatamente após a colheita, sendo as raízes filmadas e, posteriormente, quantificadas através do programa SIARCS $^{\circledR}$ (CRESTANA; GUIMARÃES; JORGE, 1994; JORGE et al., 1996). Foram abertas 4 trincheiras por tratamento, com $0,50 \mathrm{~m}$ de profundidade por $0,75 \mathrm{~m}$ de largura, a partir do centro da touceira. O perfil foi nivelado com o auxílio de uma pá reta e as raízes foram expostas com rolo escarificador. As raízes foram pintadas individual- 
mente com tinta branca para um bom contraste com o solo (CINTRA; NEVES, 1996). Para auxiliar na tomada das imagens com câmera de vídeo, foi fixada na parede do perfil uma moldura de madeira com fios de nylon, dividindo a área em quadros de 0,25 por $0,25 \mathrm{~m}$. As imagens de cada quadro foram digitalizadas por uma placa digitalizadora para IBMPC, com resolução espacial igual a 512 x 512 pixels e 256 tons de cinza. Com o Programa SIARCS ${ }^{\circledR}$, determinou-se a área das raízes em cada quadro. Para analisar a diferença de distribuição das raízes nos perfis, os dados de área de raízes em cada quadro filmado foram analisados num esquema fatorial, sendo os fatores o tratamento (doses de vinhaça), a distância lateral da touceira e a profundidade. Foram efetuadas também análises de regressão entre as doses de vinhaça e a quantidade total de raízes.

\section{Resultados e Discussão}

Os resultados referentes à produtividade de colmos de cana são apresentados na Figura 1. Pode-se observar que houve aumento da produtividade com o aumento da dose de vinhaça, até a dose de $300 \mathrm{~m}^{3} \mathrm{ha}^{-1}$. Aumentos adicionais na dose de vinhaça, nos tratamentos com 450 e $600 \mathrm{~m}^{3} \mathrm{ha}^{-1}$, provocaram redução, embora não significativa, na produtividade da cana. Penatti et al. (1988), aplicando doses crescentes de vinhaça $\left(0,50,100\right.$ e $\left.150 \mathrm{~m}^{3} \mathrm{ha}^{-1}\right)$ e nitrogênio $(0,50$, 100 e $\left.150 \mathrm{~kg} \mathrm{ha}^{-1}\right)$ em Latossolo Vermelho Amarelo com a variedade SP70-1143 ( $3^{\circ}$ corte) e Latossolo Roxo com a variedade SP71-1406 (2 $2^{\circ}$ corte), verificaram que, em ambos estudos, a vinhaça também proporcionou aumentos significativos de produção e aumento do teor de potássio, conforme o aumento das doses.

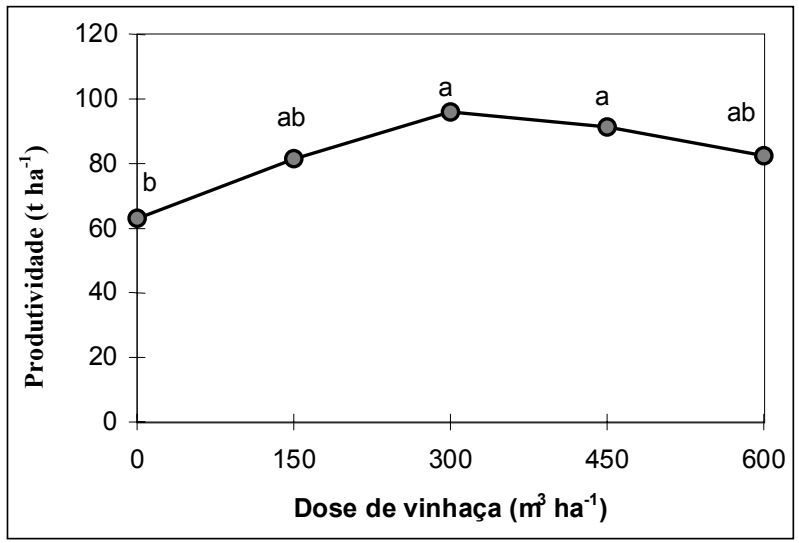

Figura 1 - Produtividade de cana-de-açúcar submetida a doses de vinhaça. Médias seguidas da mesma letra não diferem estatisticamente pelo teste de Tukey, no nível de $5 \%$ de significância.

Os resultados referentes à área radicular total nos perfis encontram-se na Tabela 2. Observa-se que houve tendência de aumento do enraizamento à medida que se aumentou a dose de vinhaça aplicada, sendo a dose $600 \mathrm{~m}^{3} \mathrm{ha}^{-1}$ significativamente superior às doses 0 e $150 \mathrm{~m}^{3} \mathrm{ha}^{-1}$. A equação de regressão calculada foi $\mathrm{y}=137,19+0,17 \mathrm{x}(\mathrm{p}<0,05)$, com $\mathrm{R}^{2}$ $=0,33$, sendo y a área de raízes e $\mathrm{x}$ a dose de vinhaça.

Tabela 2 - Área $\left(\mathrm{em} \mathrm{cm}^{2}\right)$ média do total das raízes de cana-de-açúcar (variedade RB 785148) para os tratamento de vinhaça (média de quatro repetições).

\begin{tabular}{cc}
\hline Vinhaça & Área \\
\hline $\mathrm{m}^{3} \mathrm{ha}^{-1}$ & $\mathrm{~cm}^{2}$ \\
\hline 0 & $140,6 \mathrm{bc}$ \\
150 & $137,0 \mathrm{c}$ \\
300 & $226,8 \mathrm{ab}$ \\
450 & $201,7 \mathrm{abc}$ \\
600 & $236,7 \mathrm{a}$ \\
\hline C.V. (\%) & 29,086
\end{tabular}

* Médias seguidas da mesma letra não diferem estatisticamente pelo teste de Duncan, no nível de 5\% de significância. 
Observa-se na Tabela 3 os resultados referentes à distribuição de raízes por profundidade. Verificase que, independentemente de tratamento, há maior concentração de raízes na camada de 0 a $0,25 \mathrm{~m}$. Estes resultados assemelham-se aos obtidos por Medina (1993), sobre o enraizamento da cana-deaçúcar em Terra Roxa Estruturada distrófica. Neste trabalho, concluiu-se que a quantidade de íons aplicada pode induzir o enraizamento nas camadas superficiais (0,20-0,30 m). Inforzato e Alvarez (1957) também obtiveram resultados semelhantes, relatando que $59,3 \%$ do sistema radicular encontravam-se nos primeiros $0,30 \mathrm{~m}$ de solo. Comparando-se os tratamentos na camada de 0 a $0,25 \mathrm{~m}$, nota-se o efeito positivo da aplicação de vinhaça sobre o crescimento radicular, o que se confirma pela equação de regressão: $\mathrm{y}=16,50+0,08 \times(\mathrm{p}<0,05)$, com $\mathrm{R}^{2}=$ 0,80 , sendo y a área de raízes e $\mathrm{x}$ a dose de vinhaça.

Tabela 3 - Área de raízes de cana-de-açúcar nos quadros (em $\mathrm{cm}^{2}$ de raiz por $0,0625 \mathrm{~m}^{2}$ de solo) nas profundidades de $0,0-0,25$ e $0,25-0,50 \mathrm{~m}$, variedade RB 785148, submetida a doses de vinhaça (médias de 12 observações).

\begin{tabular}{|c|c|c|c|}
\hline & \multicolumn{2}{|c|}{ Profundidade $(\mathrm{m})$} & Média \\
\hline \multirow{2}{*}{$\begin{array}{l}\text { Vinhaça } \\
\mathrm{m}^{3} \mathrm{ha}^{-1}\end{array}$} & $0,0-0,25$ & $0,25-0,50$ & \\
\hline & \multicolumn{3}{|c|}{ Área de raízes $\left(\mathrm{cm}^{2} / 0,0625 \mathrm{~m}^{2}\right)$} \\
\hline 0 & $28,2 \mathrm{Ab}$ & $18,6 \mathrm{Aa}$ & 23,4 \\
\hline 150 & $29,3 \mathrm{Ab}$ & $16,4 \mathrm{Ba}$ & 22,8 \\
\hline 300 & $44,4 \mathrm{Aa}$ & $31,2 \mathrm{Ba}$ & 37,8 \\
\hline 450 & $38,7 \mathrm{Aab}$ & $28,5 \mathrm{Aa}$ & 33,6 \\
\hline 600 & $56,7 \mathrm{Aa}$ & $22,2 \mathrm{Ba}$ & 39,4 \\
\hline Média & 39,4 & 23,4 & \\
\hline D.M.S. & 11,20 & 11,20 & \\
\hline
\end{tabular}

* Médias seguidas da mesma letra maiúscula na linha e minúscula na coluna, não diferem estatisticamente pelo teste de Tukey, no nível de $5 \%$ de significância.

Os resultados de distribuição de raízes em diferentes distâncias da touceira em relação às doses de vinhaça aplicadas encontram-se na Tabela 4. Observa-se que, independente das doses, quanto maior a distância da touceira, menor a quantidade de raízes. Em todas as distâncias, as doses 300, 450 e $600 \mathrm{~m}^{3}$ $\mathrm{ha}^{-1}$ resultaram em áreas radiculares maiores que as da testemunha e da dose de $150 \mathrm{~m}^{3} \mathrm{ha}^{-1}$ de vinhaça.

Tabela 4 - Área de raízes de cana-de-açúcar nos quadros (em $\mathrm{cm}^{2}$ de raiz por $0,0625 \mathrm{~m}^{2}$ de solo) nas distâncias da touceira de 0,0-0,25 e 0,25-0,50 e 0,50$0,75 \mathrm{~m}$, variedade RB 785148 submetida a doses de vinhaça (médias de 12 observações).

\begin{tabular}{ccccc}
\hline & \multicolumn{3}{c}{ Distância da touceira $(\mathrm{m})$} & Média \\
\cline { 1 - 3 } Vinhaça & $0,0-0,25$ & $0,25-0,50$ & $0,50-0,75$ \\
\cline { 2 - 4 } $\mathrm{m}^{3} \mathrm{ha}^{-1}$ & \multicolumn{4}{c}{ Raízes $\left(\mathrm{cm}^{2} / 0,0625 \mathrm{~m}^{2}\right)$} \\
\cline { 2 - 4 } & 36,5 & 21,5 & 12,3 & 23,4 \\
150 & 36,1 & 19,9 & 12,4 & 22,8 \\
300 & 51,2 & 34,4 & 27,7 & 37,8 \\
450 & 38,2 & 34,8 & 27,8 & 33,6 \\
600 & 51,5 & 37,8 & 29,1 & 39,5 \\
\hline Média & $42,71 \mathrm{a}$ & $29,71 \mathrm{~b}$ & $21,86 \mathrm{c}$ & \\
\hline D.M.S. & 7,43 & 7,43 & 7,43 & \\
\hline
\end{tabular}

* Médias seguidas da mesma letra não diferem estatisticamente pelo teste de Tukey, no nível de 5\% de significância.

Somando-se os resultados de enraizamento em relação à distância da touceira, em que as doses 300 , 450 e $600 \mathrm{~m}^{3} \mathrm{ha}^{-1}$ de vinhaça mostraram-se equivalentes e superiores à testemunha e à dose $150 \mathrm{~m}^{3} \mathrm{ha}^{-1}, \mathrm{com}$ os resultados de enraizamento em relação à profundidade, em que a dose de $300 \mathrm{~m}^{3} \mathrm{ha}^{-1}$ resultou em maior área radicular na camada de 0,25 a $0,50 \mathrm{~m}$, o tratamento com a dose de $300 \mathrm{~m}^{3} \mathrm{ha}^{-1}$ de vinhaça foi o melhor dentre os testados neste estudo, resultando, ainda, em produtividade superior à da testemunha e levemente maior que as observadas nos outros tratamentos.

Estes resultados indicam que doses acima de 300 $\mathrm{m}^{3} \mathrm{ha}^{-1}$ não são vantajosas neste tipo de solo. Além 
de não resultarem em ganhos de produção, aumentam os custos de produção devido ao transporte e à aplicação do subproduto.

\section{Conclusões}

Para as condições estudadas, conclui-se que:

- a vinhaça aplicada nas doses de 300 e $450 \mathrm{~m}^{3} \mathrm{ha}^{-1}$ proporciona maiores produtividades de colmos;

- a dose de $300 \mathrm{~m}^{3} \mathrm{ha}^{-1}$ de vinhaça resulta em maior enraizamento na camada de 0,25 a 0,50 $\mathrm{m}$ de profundidade; e

- a aplicação de vinhaça aumenta a área total raízes, principalmente na profundidade de 0 a $0,25 \mathrm{~m}$.

\section{Referências}

BÖHM, W. Methods of studying root systems. Berlin: Springer-Verlag, 1979.

CINTRA, F. L. D.; NEVES, C. S. V. J. Aspectos metodológicos do estudo do sistema radicular de plantas perenes através de imagens. Boletim Informativo da Sociedade Brasileira de Ciência do Solo, Campinas, v.21, n.3, p.91-94, 1996.

CRESTANA, S. et al. Avaliação da distribuição de raízes no solo auxiliada por processamento de imagens digitais. Revista Brasileira de Ciência do Solo, Campinas, v.18, p.365-371, 1994.
CORRÊA, A. R.; GODOY, H.; BERNARDES, L. R. M. Características climáticas de Londrina. 2.ed. Londrina: IAPAR, 1982.

GLÓRIA, N. A.; ORLANDO FILHO, J. Aplicação de vinhaça como fertilizante. Boletim Técnico do Planalsucar, Piracicaba, v.5, p.5-38, 1983.

INFORZATO, R.; ALVAREZ, R. Distribuição do sistema radicular da cana-de-açúcar var. Co 290, em solo tipo terra roxa legítima. Bragantia, Campinas, v.16, n.1, p.113, 1957.

JORGE, L. A. C. et al. Aquisição de imagens de raizes. São Carlos: EMBRAPA, 1996. CDROM.

KORNDÖRFER, G. H.; PRIMAVESI, O.; DEUBER, R. Crescimento e distribuição do sistema radicular da cana-deaçúcar em solo LVA. Boletim Técnico Coopersucar, São Paulo, v.47, p.32-36, 1989.

MEDINA, C. C. Estudo da aplicação de gesso, calcário e vinhaça na produção e enraizamento da cana-de-açúcar (Saccharum spp). 1993. 175f. Tese (Doutorado em Agronomia) - UNESP, Botucatu.

PENATTI, C. P. et al. Efeitos da aplicação de vinhaça e nitrogênio na soqueira da cana-de-açúcar. Boletim Técnico Coopersucar, São Paulo, v.44, p.32-38, 1988.

PLANALSUCAR. Novas variedades $R B$ para a região Centro Sul do Brasil. Piracicaba, 1988. p.16-20. 
